\title{
Novel Classes of Responsive and Unresponsive C Nociceptors in Human Skin
}

\author{
Roland Schmidt, ${ }^{1}$ Martin Schmelz, ${ }^{2}$ Clemens Forster, ${ }^{2}$ Matthias Ringkamp, ${ }^{2}$ Erik Torebjörk, ${ }^{1}$ and Hermann \\ Handwerker ${ }^{2}$ \\ 'Department of Clinical Neurophysiology, University Hospital, Uppsala, S-75185 Sweden and 'Department of Physiology \\ and Biocybernetics, University of Erlangen/Nürnberg, Germany
}

\begin{abstract}
One hundred ninety-four cutaneous $\mathrm{C}$-fibers were recorded from the human peroneal nerve; 118 units were found by mechanical stimuli and 76 units were detected by electrical stimulation through a surface electrode. Needle electrodes were then inserted for electrical intradermal stimulation in the innervation territory of the units. Afferent and efferent sympathetic $\mathrm{C}$-fibers were identified by slowing of conduction velocity after activation either by physical or chemical skin stimuli, or by arousal maneuvers eliciting sympathetic reflexes.
\end{abstract}

In addition to mechano-heat-responsive $\mathrm{C}$ units (CMH) also found in previous studies, we here report on novel classes of $\mathrm{C}$ nociceptors in human skin, namely, units responding only to mechanical stimuli (CM), units responding only to heating $(\mathrm{CH})$, and units that were insensitive to mechanical and heating stimuli and also to sympathetic provocation tests $\left(\mathrm{CM}_{\mathrm{i}} \mathrm{H}_{\mathrm{i}}\right)$.

With the electrical search technique we found $45 \% \mathrm{CMH}$, $13 \% \mathrm{CM}, 6 \% \mathrm{CH}, 24 \% \mathrm{CM}_{\mathrm{i}} \mathrm{H}_{\mathrm{i}}$, and $12 \%$ sympathetic units. Excitation by topically applied mustard oil occurred in $\mathbf{5 8 \%}$ of $\mathrm{CMH}$ units, and in one-third of $\mathrm{CM}$ and $\mathrm{CM}_{\mathrm{i}} \mathrm{H}_{\mathrm{i}}$ units, respectively.

Some $\mathrm{CM}, \mathrm{CH}$, and $\mathrm{CM}_{\mathrm{i}} \mathrm{H}_{\mathrm{i}}$ units were sensitized to heating and/or to mechanical stimuli after topical application of mustard oil or capsaicin. These units then acquired responsiveness to a stimulus modality to which they previously were insensitive. Such recruitment of previously silent nociceptors implies spatial summation to the nociceptive barrage at central levels, and may contribute both to primary hyperalgesia to heat and pressure after chemical irritation, and to secondary hyperalgesia as a consequence of central sensitization.

[Key words: microneurography, human nociceptors, C-fibers, sensitization, pain, hyperalgesia]

Since the first successful microneurographic experiments on afferent C-fibers in humans (Hallin and Torebjörk, 1970; Torebjörk and Hallin, 1970), most units recorded from the cutaneous

\footnotetext{
Received Apr. 26, 1994; June 1, 1994; accepted June 16, 1994.

This work was supported by the Swedish Medical Council, Project 5206, The Bank of Sweden Tercentenary Foundation (Guest Professorship for H.H.), and the Deutsche Forschungsgemeinschaft (SFB 353). We thank Dr. Raimondo Traversa, who participated in some of the experiments.

Correspondence should be addressed to Professor Erik Torebjörk at the above address.

Copyright (C) 1995 Society for Neuroscience $0270-6474 / 95 / 150333-09 \$ 05.00 / 0$
}

innervation territories of the radial and peroneal nerves were found to respond to mechanical stimuli and heating (for reviews, see Vallbo et al., 1979; Handwerker and Kobal, 1993). These units were classified as $\mathrm{C}$ polymodal nociceptors (Bessou and Perl, 1969) or C mechano-heat (CMH) nociceptors (Campbell et al., 1989). However, it has long been recognized that there exists in the monkey skin a rich diversity of $\mathrm{C}$ nociceptors that respond differentially to mechanical, mechanothermal, or thermal stimuli (Georgopoulos, 1976). Recently, improved experimental techniques with electrical search stimuli (Meyer and Campbell, 1988) have led to the discovery of very high threshold or insensitive cutaneous nociceptors that were primarily activated by inflammation processes. They seem to be frequent in the hairy skin of monkey (Meyer et al., 1991; Davis et al., 1993) and rat (Handwerker et al., 1991b; Kress et al., 1992) and also in noncutaneous tissues such as the knee joint (Schaible and Schmidt, 1985, 1988; Grigg et al., 1986) and the urinary bladder of cat (Häbler et al., 1988, 1990). Some of these unresponsive units were activated and/or sensitized to subsequent mechanical and thermal stimulation by chemical irritant substances (Neugebauer et al., 1989; Handwerker et al., 1991b; Kress et al., 1992; Davis et al., 1993). Moreover, the study of different forms of hyperalgesias in man has led to the theoretical assumption of purely chemosensitive nociceptors in human skin (LaMotte, 1988, 1992; LaMotte et al., 1988, 1991).

The purpose of this study was to search for a spectrum of $\mathrm{C}$ nociceptors of various classes, including the insensitive or chemosensitive ones, in human skin. To this purpose we changed the experimental protocol from the traditional mechanical search stimuli to a search procedure employing electrical stimuli (or a combination of mechanical and electrical stimuli) to recruit units independently of their sensitivity to natural stimulation. In addition, a computerized version of a method utilizing interactions betwecn naturally and electrically evoked discharges (Hallin and Torebjörk, 1974b; Torebjörk, 1974; Torebjörk and Hallin, 1974) allowed reliable testing of the responsiveness of individual $\mathrm{C}$ units in multiunit recordings frequently encountered in microneurography. By this method the yield of individual experiments was greatly increased.

Preliminary results have been published in abstract form (Handwerker et al., 1993).

\section{Materials and Methods}

The experiments were carried out in the microneurography laboratories at Uppsala and Erlangen. Of the 40 experimental sessions, 31 were performed with male and nine with female subjects. Age range was 1929 years. None of the subjects showed signs of neurological or derma- 
tological disease. All of them gave their informed consent and the study was approved by the local ethics committees.

Conventional microneurography techniques were employed to record from C-fibers in the peroneal nerve (Torebjörk, 1974). In 30 cases we recorded from cutaneous fascicles in the common peroneal nerve dorsolateral to the fibular head and in 10 cases from the superficial branch of this nerve proximal to the ankle.

Search for $C$-fiber units. When the tip of the recording electrode had reached a stable position in a cutaneous nerve fascicle, the skin field innervated by this fascicle was mapped by gently stroking the skin and listening to the high-pitched sound from multifiber discharges in lowthreshold mechanosensitive A-fibers. Subsequently, one of two search strategies was employed for identification of C-fibers, as follows.

Mechanical search strategy. The skin within the A-fiber territory was scratched with a small wooden stick, or folds of the skin were squeezed at an intensity that was barely painful. Afferent $\mathrm{C}$-fiber responses were identified by their low-frequency signal content, their long latencies, and their typical afterdischarges.

Electrical search strategy. A pointed steel electrode with a tip area of $1 \mathrm{~mm}^{2}$ was gently pressed to the skin and single electrical pulses of 0.2 sec duration were delivered from an isolated constant voltage stimulator (Grass S48 or S8). Electrode gel was used to reduce the impedance. Stimulus strength was adjusted approximately to the pain threshold of the subject and/or to an intensity inducing but slight twitches of underlying muscles (i.e., to $60-100 \mathrm{~V}$ ). This electrical stimulus was used to search the fascicular territory carefully, until a C-fiber response was obtained.

Intracutaneous electrical stimulation. Once the innervation territory of a $C$ unit was found, the respective skin site was encircled with a pen and a pair of uninsulated steel needles, $0.3 \mathrm{~mm}$ in diameter, were inserted intracutaneously with one needle inside the innervation territory and the other placed transversely at a distance of $5-10 \mathrm{~mm}$. We then used the needle electrodes for continuously stimulating this and other adjacent $C$ units at intervals of $3-4$ sec at a moderately painful intensity $(10-30 \mathrm{~V}, 0.2 \mathrm{msec})$. Mechanosensitive fibers could always be stimulated electrically if the needles were properly inserted within their receptive fields, and, in addition, the intracutaneous stimulation would also excitc adjacent mechanoinsensitive units.

Identification of sympathetic and afferent $C$ units. At low frequency of intracutaneous electrical stimulation at constant intensity, the latencies of the evoked C-fiber responses were fairly stable, except for slow shifts due to posttetanic effects on a newly recruited fiber (Torebjörk and Hallin, 1974) or due to gradual changes in tissue temperature (see Fig. 8), or abrupt flip-flop shifts due to stimulation of different branches of the same parent axon (Torebjörk, 1974; Torebjörk and Hallin, 1974). However, if one of the electrically excited $\mathrm{C}$ units was also activated by some additional stimulus, the latency of that particular unit would increase due to conduction slowing during the relative refractory period (Torebjörk and Hallin, 1974). This has turned out to be a very sensitive "marking" of the activated units and has allowed a reliable differentiation between efferent $\mathrm{C}$ units firing during sympathetic reflexes and afferent $\mathrm{C}$ units responding to defined natural stimulation of the skin (Hallin and Torebjörk, 1974b; Torebjörk, 1974; Torebjörk and Hallin, 1976). Electrically excited C units were usually tested in the following order.

(1) Maneuvers eliciting sympathetic reflexes. Electrically excited C units were regularly tested for possibly being sympathetic by maneuvers known to increase greatly the skin sympathetic sudomotor and vasoconstrictor outflow in conscious man (Torebjörk and Hallin, 1970; Delius et al., 1972; Hagbarth et al., 1972). Sympathetic reflexes were provoked through loud noises unexpected for the subject, or by inciting the subject to laugh or to perform a deep inspiration. The efficiency of these maneuvers was controlled by recording massive bursts of sympathetic discharges.

(2) Natural stimulation of the skin. For quantitative mechanical stimulation a set of calibrated von Frey nylon filaments was used (Stoelting Co., Chicago, IL). Heat stimuli were delivered from a light bulb either while measuring the skin temperature in the receptive field with a thermistor attached to the skin, or while employing a device by which the temperature was feedback controlled from a thermocouple gently attached to the skin (Beck et al., 1974). In both cases the skin temperature was slowly increased, typically by $0.25^{\circ} \mathrm{C} / \mathrm{sec}$, from an adapting temperature of $30-32^{\circ} \mathrm{C}$. Heating was stopped on demand of the subject before a level was reached at which involuntary withdrawal reflexes would have been threatening. With this method we were able to raise the local skin surface temperature to $48^{\circ} \mathrm{C}$ and in some cases up to $52^{\circ} \mathrm{C}$.
Cold stimuli were applied by placing small pieces of ice onto the receptive field.

Several ascending series of mechanical and thermal stimuli were performed to establish thresholds and suprathreshold responsiveness of the afferent units. For insensitive units the test area was expanded to cover a circle with a radius of at least $3 \mathrm{~cm}$ around the stimulating electrodes inserted in the skin.

(3) Chemical irritants. After completing the first series of natural stimuli, the area from which the respective unit was expected to be recruited was treated with mustard oil $(100 \%$ solution of allyl-isothiocyanate; Merck, Darmstadt, Germany) for 3-5 min. For this purpose pieces of filter paper soaked in mustard oil were placed on the skin and covered with a plastic film to prevent evaporation. After removing the mustard oil the treated skin area was reddened. It was then tested again with natural stimuli. Thereafter, this skin area was similarly treated with a solution containing $1 \%$ capsaicin dissolved in ethanol for $30 \mathrm{~min}$, and if the recording was still stable, natural stimuli were done before the experiment was terminated. Both chemical irritants caused moderate ongoing burning pain.

Data acquisition and analysis. $\mathrm{C}$ unit responses to intracutaneous electrical stimulation were recorded on line by a $\mathrm{PC}$ computer via an interface card (DAP, Microstar, USA) using the SPIKE/SPIDI software package (Forster and Handwerker, 1990). A suitable time segment of the recording following each electrical stimulus pulse was displayed and subsequent traces were written from top to bottom on the computer screen for on-line assessment of latency shifts of the activated $C$ units (see Fig. 1). In addition, the recordings were stored on hard disk for offline analysis. Prior to final off-line evaluation, a digital filter squaring the data points was applied, resulting in an enlargement of the spiketo-noise ratio. By that means the spikes were enhanced and the lower noise peaks attenuated. In addition, the program provides a facility to eliminate background noise not surpassing predetermined levels. In most figures only events are shown that surpassed preselected threshold levels marked by dotted lines in the specimen records. After such signal treatment, a careful reevaluation and final assessment was madc regarding the identity and responsiveness of all stable $C$ units that were reliably discriminated from the noise.

\section{Results}

\section{Sample of $C$ units}

One hundred ninety-four $C$ units were analyzed. Of these, 118 units were found with the mechanical and 76 units with the electrical search strategy. Conduction velocities ranged from 0.44 to $1.4 \mathrm{~m} / \mathrm{sec}$. The triphasic, mainly negative action potentials with durations of the order of $2 \mathrm{msec}$ provide further evidence that recordings were obtained from $\mathrm{C}$ fibers.

\section{Mechanoresponsive units}

Seventy-five percent of the units out of the sample collected with the mechanical search technique and $58 \%$ of the units encountered by searching electrically were mechanically excited by stimulation with von Frey filaments up to $1.2 \mathrm{~N}$. Figure 1 shows an example of three units recorded simultaneously. Whereas the unit labeled $a$ was insensitive to mechanical (and heat) stimuli, units $b$ and $c$ were activated from the same skin site. Unit $b$ had a lower mechanical threshold and was activated by a von Frey filament exerting a pressure of $15 \mathrm{mN}$, whereas unit $c$ required a stronger filament to become excited. Both units showed graded responses to suprathreshold stimuli in the noxious intensity range, as seen by the pronounced conduction delays following stimulation with a rather stiff von Frey filament of $2.6 \mathrm{~N}$.

The distribution of mechanical thresholds of 80 units activated by stimulation with von Frey filaments is represented in Figure 2.

\section{$C M H$ and $C M$ units}

Mechanically responsive $\mathrm{C}$ units were subdivided in $\mathrm{CMH}$ units being also heat sensitive, and in $\mathrm{CM}$ units that were not excited 

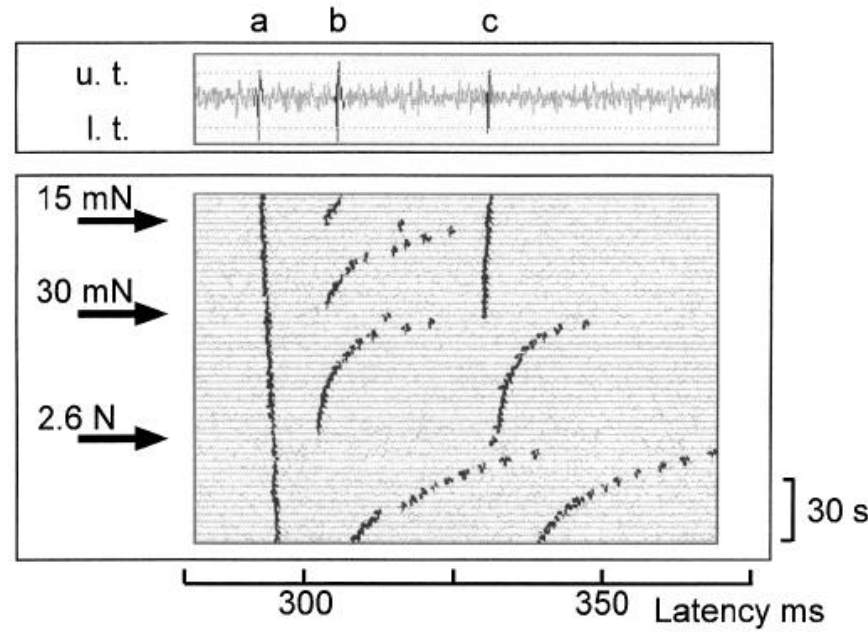

Figure 1. The top panel shows responses of $\mathrm{C}$ units to intracutaneous electrical stimulation. Three units (labeled $a, b$, and $c$ ) that exceed the upper (u.t.) and/or lower (l.t.) trigger levels are highlighted. The bottom panel shows, from top to bottom, successive recordings of the same units during electrical stimulation at $3 \mathrm{sec}$ intervals (time scale to the right). Unit $a$ did not respond to mechanical probing with different von Frey filaments (marked by arrows to the left). Unit $b$ responded to stimuli of $15 \mathrm{mN}$ and stronger, as indicated by marked increases of latency after each activation. Unit $c$ responded to $30 \mathrm{mN}$ and stronger stimuli. The latency after the electric shocks is indicated below.

by heating up to the subject's tolerance level (see Materials and Methods). $\mathrm{CMH}$ units were more frequently found $(n=87)$ than CM units $(n=45)$ and accounted for about $66 \%$ of all mechanoresponsive units. The mechanical thresholds of $\mathrm{CMH}$ and $\mathrm{CM}$ units were similar. Thresholds of $\mathrm{CMHs}$ ranged from 3.4 to $750 \mathrm{mN}$ with a median of $30 \mathrm{mN}$, thresholds of CMs from $14 \mathrm{mN}$ to $360 \mathrm{mN}$, also with a median of $30 \mathrm{mN}$. Thus, there was no statistical difference between the groups. Both $\mathrm{CMH}$ and $\mathrm{CM}$ units exhibited greater increases in latency in response to suprathreshold stimulation with von Frey filaments of increasing stiffness, implying graded responses into the noxious intensity range.

An example of a CMH unit stimulated with radiant heat is shown in Figure 3. In this experiment the skin temperature was first adapted to $32^{\circ} \mathrm{C}$ and then raised to $49^{\circ} \mathrm{C}$ at $0.25^{\circ} \mathrm{C} / \mathrm{sec}$. Heating the receptive field of the $\mathrm{CMH}$ unit first led to a shortened conduction delay due to warming of the terminal conduc-

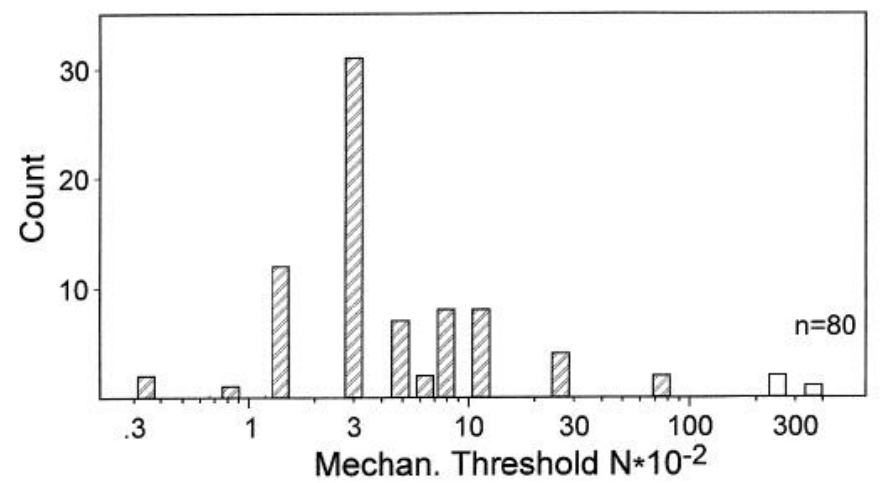

Figure 2. Mechanical thresholds of $80 \mathrm{C}$ units activated with von Frey filaments. Force on the horizontal logarithmic scale is expressed as $\mathrm{N}$ $\times 10^{-2}$. Units with mechanical thresholds exceeding $1.6 \mathrm{~N}$ were regarded as mechanoinsensitive (open columns).
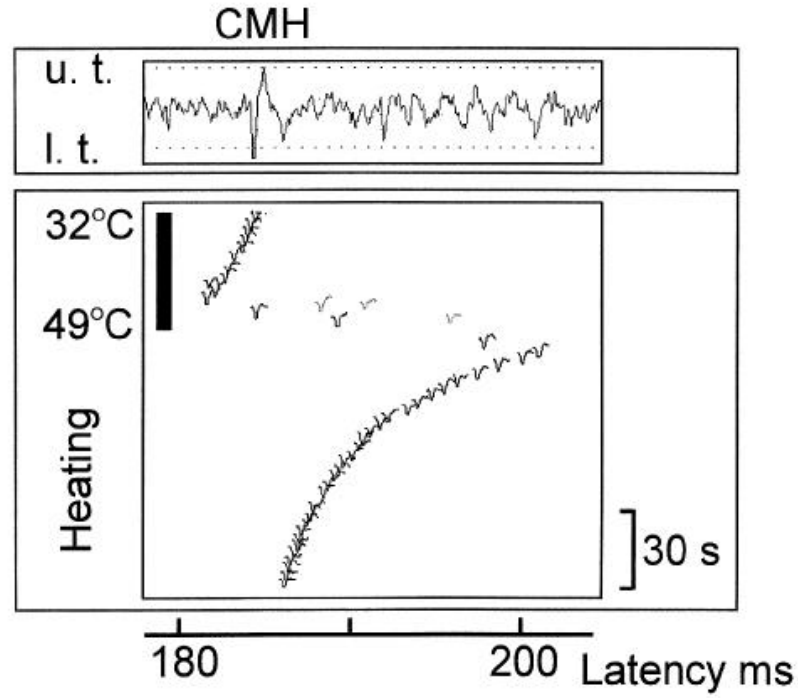

Figure 3. Mechano-heat-sensitive $\mathrm{C}$ unit $(C M H)$ stimulated by heating the skin from $32^{\circ} \mathrm{C}$ to $49^{\circ} \mathrm{C}$ at $0.25^{\circ} \mathrm{C} / \mathrm{sec}$ (thick vertical bar) while responding to electrical stimulation in the receptive field as shown in the top panel. Only spikes exceeding the upper (u.t.) and/or lower (l.t.) trigger levels are shown as successive recordings in the bottom panel. Note the acceleration of the conduction velocity due to warming before the unit started to respond, and then the dramatic slowing of conduction due to heat activation of the unit.

tive nerve membrane. With further increase in temperature, there was instead a pronounced increase in latency, clearly "marking" that the unit had been activated by the heat stimulus. Further examples of responses in a $\mathrm{CMH}$ unit are shown in Figure 7.

\section{$\mathrm{CH}$ units}

Six units in the entire material, and $6 \%$ of the units found with the electrical search procedure, responded to heating with

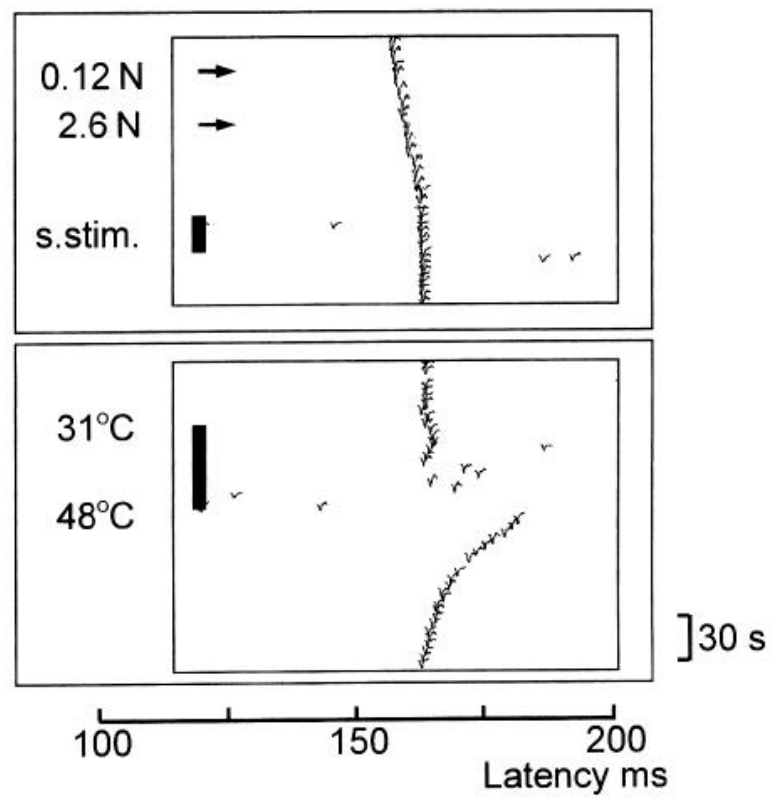

Figure 4. Heat-sensitive $\mathrm{C}$ unit $(\mathrm{CH})$ not responding to mechanical probing with different von Frey filaments (arrows) or to sympathetic provocation (s.stim.) shown in the top panel, but activated by heating the skin from $31^{\circ} \mathrm{C}$ to $48^{\circ} \mathrm{C}$ as indicated in the bottom panel. The figure shows successive responses to electrical stimulation in the receptive field at $3 \mathrm{sec}$ intervals as in Figures 1 and 3. 

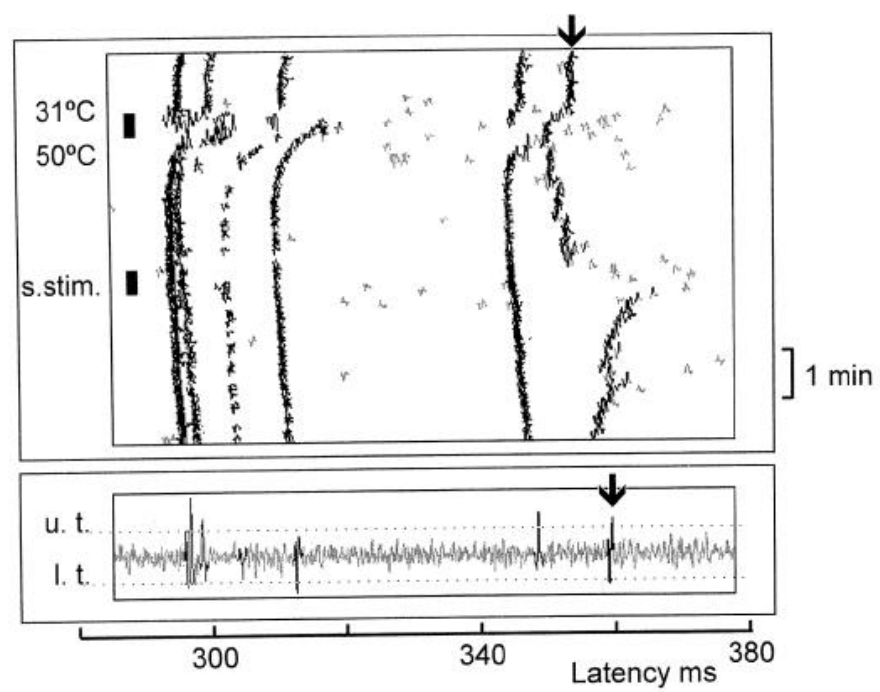

Figure 5. Top, Five CMH units with latencies of $295-350 \mathrm{msec}$ to intracutaneous electrical stimuli were responsive to heating the skin from $31^{\circ} \mathrm{C}$ to $50^{\circ} \mathrm{C}$, but unaffected by sympathetic provocation tests (s.stim.). By contrast, a sympathetic unit (arrow) at a latency around $360 \mathrm{msec}$ was not activated by heating as indicated by the passive shortening of latency. Instead the unit was spontaneously active in the absence of any intentional stimulus, as shown by the irregular increases in latency, and sympathetic reflex stimulation induced a very obvious response. Bottom, Only spikes exceeding the upper and lower trigger levels are shown

thresholds ranging from $45^{\circ}$ to $48^{\circ} \mathrm{C}$ but were not activated by mechanical stimulation even with a rather stiff von Frey filament $(1.6 \mathrm{~N})$. An example is shown in Figure 4. There were no latency shifts in response to sympathetic provocations for any of these units, excluding that the heat responses would have been due to sympathetic reflexes.

\section{Sympathetic units}

Twenty-one sympathetic units were identified. They constituted $11 \%$ of all units tested, and $12 \%$ of the units found with the electrical search strategy. None of them responded to mechan-

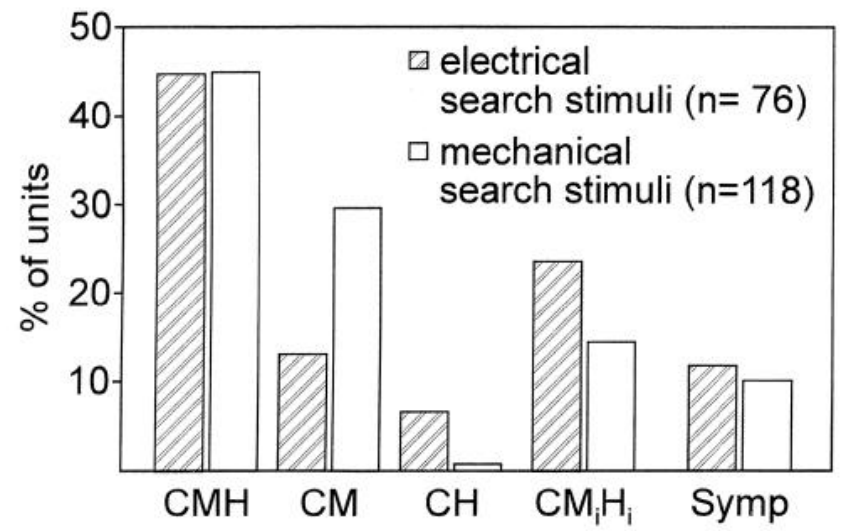

Figure 6. Proportions of $\mathrm{C}$ units of different classes found by the electrical (hatched bars) and the mechanical search strategy (open bars). For details, see Materials and Methods. It is obvious that the mechanical search technique favored detection of mechanosensitive units. With the less biassed electrical search technique, $45 \%$ were mechano-heat sensitive $(C M H), 13 \%$ were mechano-sensitive $(C M), 6 \%$ were heat sensitive $(\mathrm{CH}), 24 \%$ were insensitive to mechanical and heat stimuli $\left(\mathrm{CM}_{i} \mathrm{H}_{i}\right)$, and $12 \%$ were sympathetic efferent units $(S y m p)$.
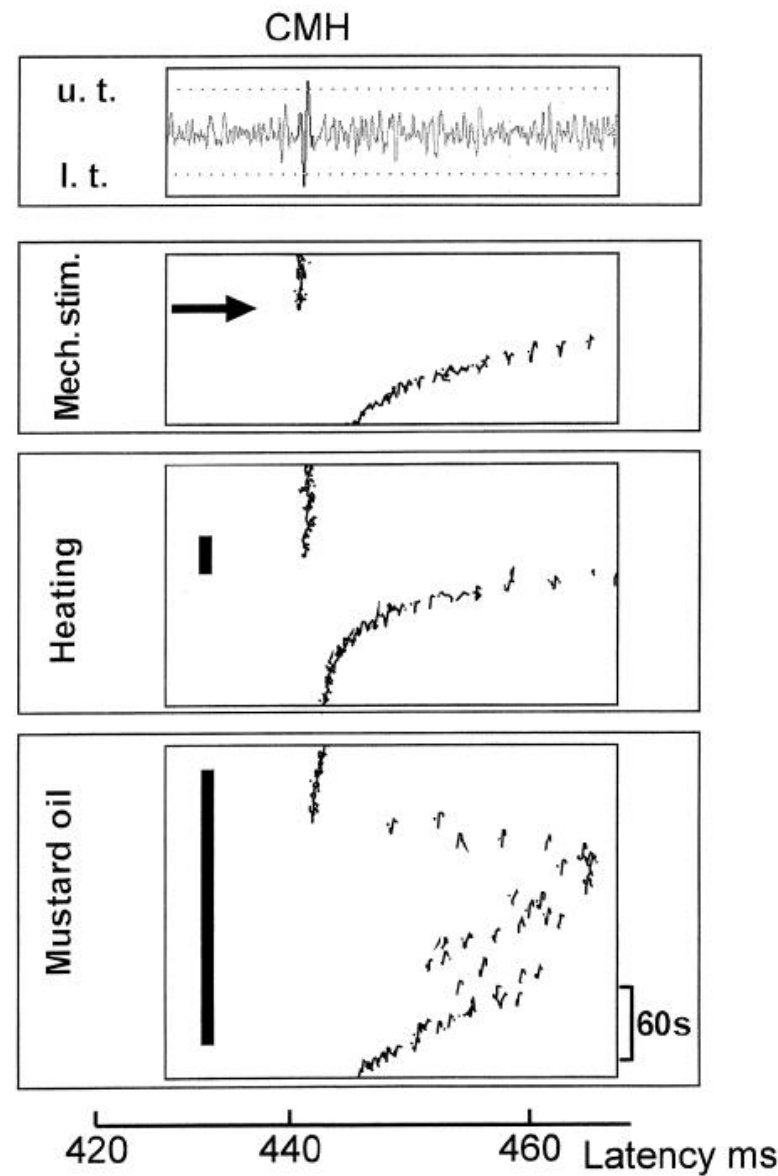

Figure 7. CMH unit (top panel) responding to mechanical stimuli (second panel) and to heating (third panel). Notice the irregular increases in latency of this unit during topical application of mustard oil (bottom panel), implying chemosensitivity.

ical or heat stimuli. In contrast to afferent $C$ units, most of them were spontaneously active, as seen by latency increases in the absence of any intentional maneuver. An example is illustrated in Figure 5. In this figure responses of six $\mathrm{C}$ units to electrical intracutaneous stimulation can be distinguished and five of them could be identified as $\mathrm{CMH}$ units responding to radiant heat (and to mechanical) stimulation. However, the slowest unit was spontaneously active as indicated by the more variable conduction delays. This unit did not respond to heat but showed marked increases in latency during sympathetic reflex provocations. On repeated reflex provocation the sympathetic $\mathrm{C}$ fiber responses tended to decrease, as a sign of habituation. This was in contradistinction from responses in mechanoresponsive $\mathrm{C}$ units that showed no signs of fatigue if von Frey stimuli for 2 $\mathrm{sec}$ were repeated at intervals of $30 \mathrm{sec}$ or more.

\section{Cooling}

Responses of afferent $\mathrm{C}$ units to cold stimuli were difficult to evaluate with the present technique. Both the direct action of the lowered temperature and the partial inactivation of the membrane in the relative refractory period after cold-induced discharges would lead to lower conduction velocities. For some $\mathrm{CM}$ and $\mathrm{CMH}$ units a low-frequency response to strongly cooling the skin to temperatures below $20^{\circ} \mathrm{C}$ could be neither excluded nor verified with certainty, since it was not possible to 
corroborate the identity of units discharging during cooling with those excited by the electrical intracutaneous stimulation.

\section{$C M_{i} H_{i}$ units}

With the mechanical search technique 17 units, and with the electrical search strategy 18 units, were encountered that did not respond to mechanical stimulation with von Frey filaments exerting forces up to $1.6 \mathrm{~N}$, which is far beyond the threshold of CMHs described in pervious microneurographic studies (Torebjörk, 1974; Van Hees and Gybels, 1981; Adriaensen et al., 1983). These units were also insensitive to heating to levels of $48^{\circ} \mathrm{C}$ or higher, that is, temperatures that also surpass the thresholds of previously described human $\mathrm{CMH}$ units (Torebjörk, 1974; Gybels et al., 1979; Torebjörk et al., 1984). None of the units were activated by sympathetic reflex provocations. Two of these unresponsive units and one $\mathrm{CH}$ unit showed increased latencies during stimulation by the strongest von Frey filaments exerting forces of 2.5 and $3.6 \mathrm{~N}$ (see Fig. 2). However, since such strong stimulation induced movements of the intracutaneous needle electrodes, we were not sure if these latency shifts were provoked by mechanical irritation from the needles or by shifting the site of the electrical stimulation along the nerve terminals. Therefore, $1.6 \mathrm{~N}$ was taken as the upper limit of mechanical responsiveness in this study. The insensitive units were labeled $\mathrm{CM}_{\mathrm{i}} \mathrm{H}_{\mathrm{i}}$, with the subscript " $\mathrm{i}$ " standing for "insensitive."

\section{Sampling bias}

Figure 6 summarizes the classes of $\mathrm{C}$ units found with both search strategies. It is seen that mechanosensitive units were more frequent, and insensitive units were less often found with the mechanical as compared with the electrical search technique. These differences are statistically significant $\left(\chi^{2}, p<0.05\right)$.

\section{Conduction velocities}

Mean conduction velocities of $\mathrm{CMH}$ units were found to be higher $(0.97 \mathrm{~m} / \mathrm{sec})$ than those of all other unit types, and this difference was statistically significant (ANOVA and NewmanKeuls post hoc test, $p<0.04$ ). The conduction velocities of the other unit classes were not significantly different from each other (CM, $0.84 \mathrm{~m} / \mathrm{sec} ; \mathrm{CH}, 0.81 \mathrm{~m} / \mathrm{sec} ; \mathrm{CM}_{\mathrm{i}} \mathrm{H}_{\mathrm{i}}, 0.80 \mathrm{~m} / \mathrm{sec}$; sympathetic, $0.77 \mathrm{~m} / \mathrm{sec}$ ).

\section{Excitation of $C$ units by mustard oil}

Sixty units were topically exposed to mustard oil for 3-5 min. Twenty-four of them were activated. Figure 7 shows an example of irregular increases in latency of the electrically evoked response in a $\mathrm{CMH}$ unit during mustard oil application.

Eleven of $19 \mathrm{CMH}$ units responded to mustard oil (58\%) and 5 of 14 of the CM units (36\%), respectively. Seven of $22 \mathrm{CM}_{\mathrm{i}} \mathrm{H}_{\mathrm{i}}$ units $(32 \%)$ were also excited. None of two sympathetic units tested were activated by that treatment.

\section{Sensitization of $C$ units by mustard oil}

Twenty-five $\mathrm{C}$ units were tested with natural skin stimuli after application of mustard oil. Out of seven $\mathrm{CM}$ units tested, three units became heat responsive. One of three $\mathrm{CH}$ units tested was excited by mustard oil and became sensitized to mechanical stimuli afterward. In the class of $\mathrm{CM}_{\mathrm{i}} \mathrm{H}_{\mathrm{i}}$ units, 2 of 15 tested units became responsive to heating but not to mechanical stimuli, a further unit was sensitized to mechanical stimulation but not to heat, and one unit was sensitized to both (Fig. 8). Thus,
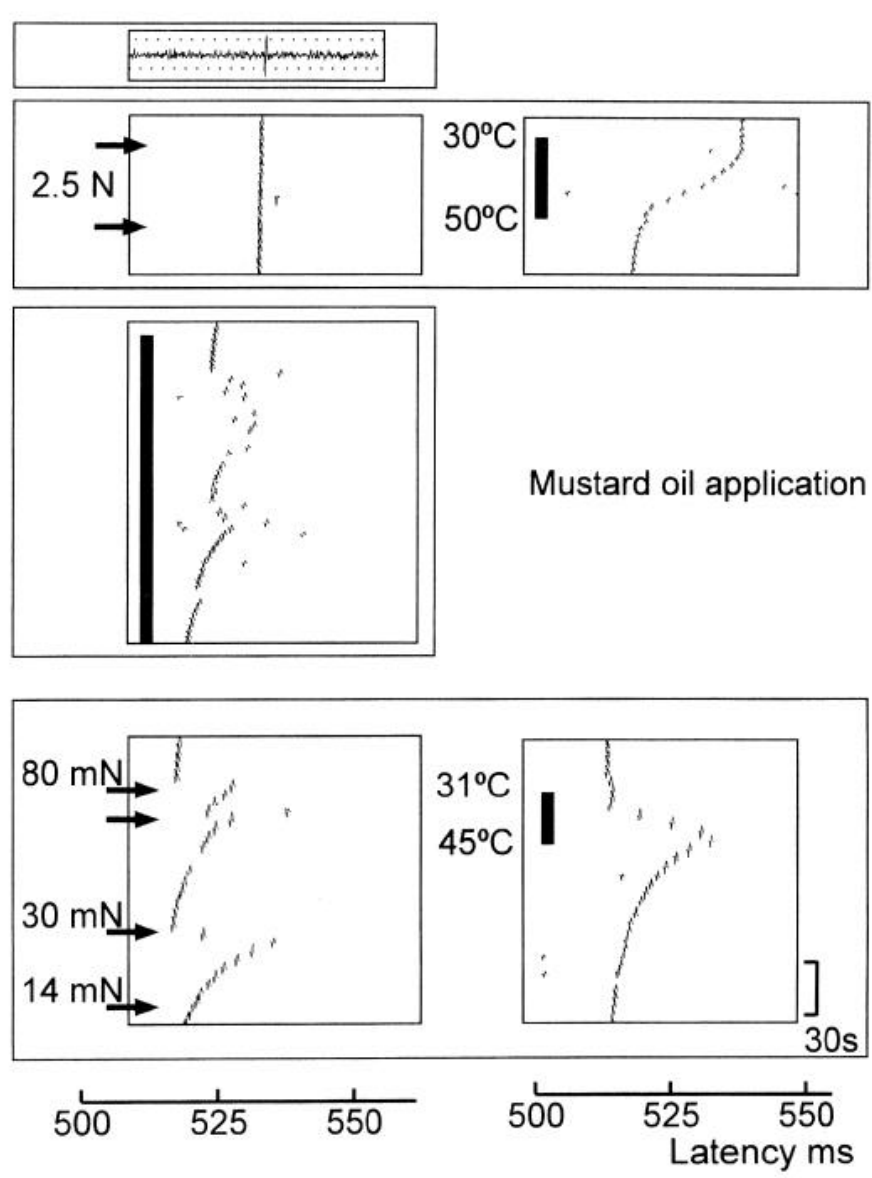

Figure 8. Sensitization of a $\mathrm{CM}_{i} \mathrm{Hi}$ unit (top panel), which was initially unresponsive to strong mechanical stimulation with von Frey filament up to $2.5 \mathrm{~N}$ and to heating from $30^{\circ} \mathrm{C}$ to $50^{\circ} \mathrm{C}$ (second panel). The unit was excited by topical application of mustard oil (third panel). After 5 min of mustard oil application, the unit was responsive to von Frey filaments down to $30 \mathrm{mN}$ and to heating from $31^{\circ}$ to $45^{\circ} \mathrm{C}$ (bottom panel). The shift in baseline latency is due to increase in skin temperature.

4 of $15 \mathrm{CM}_{\mathrm{i}} \mathrm{H}_{\mathrm{i}}$ units became sensitized to physical stimuli after treatment with mustard oil. Only two of these four units had been excited during application of this irritant substance.

\section{Excitation and sensitization by capsaicin}

For 15 units (of which 14 were not sensitized after mustard oil) the recordings were stable enough to allow subsequent testing with capsaicin applied topically for $30 \mathrm{~min}$. Two CM units were neither excited by capsaicin nor sensitized afterward. Two $\mathrm{CH}$ units were not excited by capsaicin but became responsive to mechanical stimuli afterward. One $\mathrm{CM}_{i} \mathrm{H}_{i}$ was excited by capsaicin but not sensitized. Of another $10 \mathrm{CM}_{\mathrm{i}} \mathrm{H}_{\mathrm{i}}$ units none responded to capsaicin but two units became sensitized to mechanical and heat stimuli. A third sensitized unit is shown in Figure 9. This $\mathrm{CM}_{\mathrm{i}} \mathrm{H}_{\mathrm{i}}$ unit was not activated by mustard oil, but this treatment rendered the unit responsive to stimulation with a von Frey filament of $250 \mathrm{mN}$. Subsequent application of capsaicin possibly led to a low level of excitation. After this treatment the unit was further sensitized to mechanical stimuli and responded to heat, albeit with a rather high threshold of about $48^{\circ} \mathrm{C}$.

Altogether, of $24 \mathrm{CM}_{\mathrm{i}} \mathrm{H}_{\mathrm{i}}$ units exposed to chemical irritants, 15 could be tested afterward. Of these 15 units, six were sen- 

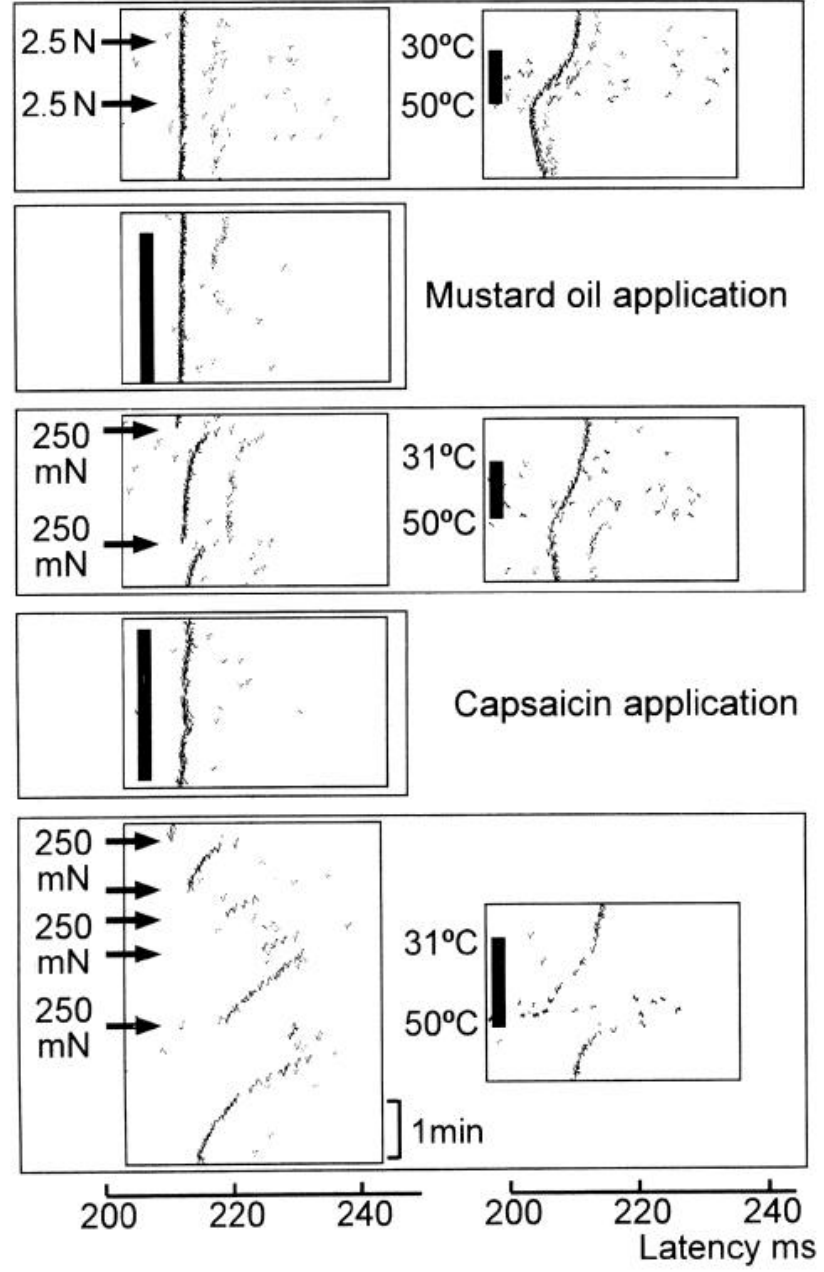

Figure 9. Sensitization of a $\mathrm{CM}_{\mathrm{i}} \mathrm{H}_{\mathrm{i}}$ unit that did initially not respond to mechanical probing $(2.5 \mathrm{~N})$, heating $\left(50^{\circ} \mathrm{C}\right)$, and mustard oil application (top two panels). After the latter procedure heat insensitivity was unchanged, but the unit could be activated by nylon filaments exerting forces of $250 \mathrm{mN}$ (third panel). After capsaicin application (fourth panel) the unit was further sensitized to mechanical stimuli and in addition heat sensitivity developed (bottom panel).

sitized to natural stimuli, but only three of them were directly activated by the chemicals.

\section{Discussion}

Two decades ago, a technique was developed to differentiate electrically evoked sympathetic and afferent C-fiber responses in cutaneous human nerves (Hallin and Torebjörk, 1974b; Torebjörk and Hallin, 1974, 1976). The basis for this technique is the characteristic slowing of impulse conduction in thin fibers that is observed after repetitive firing induced either by electrical or natural skin stimulation, or by sympathetic reflex activation. The method is sensitive enough to allow detection even of one or a few extra impulses elicited by any maneuver, as indicated by a recognizable increase in the otherwise stable response latency to electrical pulses delivered at low frequency from needle electrodes inserted into the skin (Torebjörk and Hallin, 1974). This technique has the advantage of providing definite information on the identity of the units that are activated by sympathetic reflexes or various types of natural skin stimuli. Furthermore, it can be used for detailed mapping of the receptive area of afferent units, for estimation of response thresholds, and for semiquantitative evaluation of suprathreshold response magnitude. Since C-fibers tend to aggregate and remain as neighbors for considerable distances in the human peroneal nerve (Jørum et al., 1989), several C-fibers with slightly different conduction velocities can be identified in each recording site, even if they have similar spike forms. Computer processing using dedicated software (Forster and Handwerker, 1990) greatly facilitates on-line and off-line analysis. As shown in this report, this technique has opened up the possibility of collecting large $\mathrm{C}$ unit samples in humans.

It has long been recognized that searching and identification of cutaneous afferent units by probing mechanically may have induced a sampling bias (Handwerker and Kobal, 1993). Even though we identified only one $\mathrm{C}$ unit by mechanical searching in each recording site, and then also analyzed any adjacent unit that was electrically excited from the surrounding skin area, it was obvious that this search strategy induced a considerable bias in favor of mechanosensitive $\mathrm{C}$ units (Fig. 6). However, searching with electrical stimuli delivered from a pointed probe that is systematically moved on the skin is not without bias either. This strategy will clearly favor detection of fibers with many widespread terminal branches in the skin, whereas fibers with just one or a few closely apposed endings are easily missed. This may be one explanation of why we have not encountered any warmth-specific $C$ unit in our present material, since these units typically have small spot-like receptive fields in human skin (Hensel, 1976; Hallin et al., 1982). Like for efferent fibers, afferent axons with deep endings are not likely to be recruited by this superficial search strategy. Thus, the proportions of different unit classes discussed here are only tentative, and we realize that these proportions may vary depending on different experimental approaches.

About $12 \%$ of the $\mathrm{C}$ units were identified as efferent sympathetic by their spontaneous activity and by their participation in sympathetic reflex discharges. This may be an underestimation of the proportion of sympathetic fibers in cutaneous fascicles of the peroneal nerve. We could only identify efferent fibers that were spontaneously active or excited by the maneuvers used to elicit sympathetic reflexes, that is, sudomotor and vasoconstrictor units (Jänig et al., 1983). Other types, like piloerector and vasodilator units, have no spontaneous activity (at least not in the anesthetized cat; Jänig et al., 1983) and may be activated only during specific functional states of the organism, for example, during severe exposure to cold, hypoxia, or special emotional states (Jänig, 1984). Such silent sympathetic fibers would obviously not have been recognized in our experiments; they would remain unidentified, and classified as insensitive (see below).

It is unlikely that some of the units that we classified as mechanoresponsive and/or heat responsive were in fact sympathetic fibers. This is because sympathetic fiber endings did not respond directly to the stimuli we used. Furthermore, many of the units had activation thresholds well below pain thresholds, and hence their activation would not be likely to elicit strong sympathetic reflexes. This is particular true for von Frey stimulation, which readily activates $C$ nociceptors below pain threshold (Van Hees and Gybels, 1981). Finally, sympathetic reflex responses decreased (habituated) with repetition (Hallin and Torebjörk, 1974a), a phenomenon not observed for the responses of the afferent $\mathrm{C}$ units reported here, when stimuli were applied at intervals exceeding $30 \mathrm{sec}$. 
Not surprisingly, the majority of all C-fibers (about $45 \%$ ) were classified as $\mathrm{CMH}$, that is, the conventional polymodal nociceptor type. Their mechanical thresholds, as measured during electrical stimulation, were in the same range as in other studies using conventional estimations (Torebjörk, 1974; Van Hees and Gybels, 1981; Adriaensen et al., 1983), suggesting that the electrical stimulation per se did not influence thresholds to any considerable degrcc. With the elcctrical search strategy, another $13 \%$ responded to mechanical but not to heat stimuli. Their mechanical thresholds spanned over a wide range and were not significantly different from the thresholds of $\mathrm{CMH}$ units. Furthermore, most of the CM units responded in a graded fashion to suprathreshold stimuli in the noxious intensity range, supporting the conclusion that many of them could be regarded as nociceptors. Little if any attention has been paid to this class of human nociceptors in the past. Yet, we cannot exclude that some CM units were actually low-threshold C mechanoreceptors of the type commonly encountered in hairy skin in the cat (Iggo, 1960) and less commonly found only in proximal parts of the extremities in the monkey (Kumazawa and Perl, 1977) and in the human forehead (Nordin, 1990). A typical feature of these low-threshold $\mathrm{C}$ mechanoreceptors is their responsiveness to cooling. As judged from the acoustically monitored discharges, no low-threshold cold responsive units were encountered in the present sample. However, responsiveness to this stimulus modality was not systematically studied, since lowering of temperature by itself and the repetitive firing caused by cooling both would have resulted in slowing of impulse conduction, and hence we had difficulties in differentiating these effects with our technique.

Of the remaining units identified with electrical search stimuli, $6 \%$ responded to heating, but not to mechanical stimulation. This type of $\mathrm{CH}$ unit has been reported before in animals, albeit rarely (Georgopoulos, 1976; Welk et al., 1984; Baumann et al., 1991), but it was not yet known that $\mathrm{CH}$ nociceptors also exist in human skin.

Almost 24\% of the units found with the electrical search strategy, and still about $14 \%$ of the units encountered with the mechanical search technique, were insensitive to mechanical and heating stimuli. They were labeled $\mathrm{CM}_{1} \mathrm{H}_{1}$ as suggested in a recent review (Handwerker and Kobal, 1993). Even though there are differences in search techniques and classification criteria this proportion is in a similar range as the $30 \%$ insensitive $\mathrm{C}$ units that has been found in the hairy skin in monkey (Meyer et al., 1991) and the $26 \%$ recorded in vivo and the $15 \%$ found in vitro in the hairy skin in rat (Kress et al., 1992). These units may have been either efferent or afferent. Howcver, silent and unresponsive postganglionic sympathetic units probably constitute at best a minor part of the $\mathrm{CM}_{\mathrm{i}} \mathrm{H}_{\mathrm{i}}$ population, since the proportion of efferent $\mathrm{C}$-fibers is generally much lower than that of afferent ones in nerves supplying hairy skin in mammals (Baron et al., 1988) and the piloerector and vasodilator supply is less numerous than the sudomotor and vasoconstrictor supply (Jănig, 1984). It is also conceivable that the needle electrodes in the skin excited some afferent axons at a distance from their receptive endings, and if the receptive area was not properly tested, then these units would remain "unresponsive." However, we tried to reduce this possibility by always testing large regions of skin around the stimulating electrodes when insensitive units were encountered.

The most striking argument in favor of the afferent nature of most $\mathrm{CM}_{\mathrm{i}} \mathrm{H}_{\mathrm{i}}$ units is provided by the fairly high percentage of them that were activated by irritant substances. About one-third were excited by mustard oil, and these units therefore can be regarded as chemonociceptors. However, chemonociception is probably mediated also by other unit types, since about onethird of $\mathrm{CM}$ and $\mathrm{CH}$ units and almost $60 \%$ of $\mathrm{CMH}$ units were sensitive to mustard oil. Anecdotal observations on insensitive $C$ units activated by capsaicin have been made in humans (LaMotte et al., 1992), but this is the first documentation that chemosensitive $\mathrm{CM}_{\mathrm{i}} \mathrm{H}_{\mathrm{i}}$ nociceptors constitute a substantial proportion of afferent $\mathrm{C}$ units in human skin.

It may be of interest that excitation of C-fibers by chemical irritants and sensitization to subsequent heating or mechanical stimulation were not always corresponding. A simple explanation would be that excitation needs a more profound depolarization of the receptive nerve membrane than sensitization. However, occasionally $\mathrm{CM}_{i} \mathrm{H}_{\mathrm{i}}$ units were found to be excited but not sensitized. This might hint that excitation and sensitization of afferent $\mathrm{C}$-fibers by chemical irritants could depend on different membrane processes.

Mustard oil and capsaicin are known to induce marked primary hyperalgesia to heating and also to mechanical pressure in the treated skin area (Jancsó et al., 1967; Simone et al., 1987; Szolcsanyi, 1988; Culp et al., 1989; Koltzenburg et al., 1992). Capsaicin-induced hyperalgesia to heat correlates with sensitization of $\mathrm{CMH}$ nociceptors to heating in human skin (Konietzny and Hensel, 1983; Handwerker et al., 1991a; LaMotte et al., 1992). Evidently, sensitization to heat can occur in CM and $\mathrm{CM}_{i} \mathrm{H}_{i}$ units as well, implying that these units can also contribute to primary heat hyperalgesia after chemical irritation of the skin.

The evidence for a contribution of C-fibers to experimentally induced primary mechanical hyperalgesia in humans has been mainly derived indirectly from psychophysical experiments utilizing differential nerve hlocks (Koltzenburg et al., 1992), whereas direct proof of C-fiber sensitization to von Frey filament stimulation in microneurography experiments was either absent or unconvincing (Handwerker et al., 1991a; LaMotte et al., 1992). However, previous studies have focused on the increased number of spikes in $\mathrm{CMH}$ units to a given mechanical stimulus. Only anecdotal observations on insensitive $\mathrm{C}$ units becoming sensitized to mechanical stimuli after capsaicin treatment have been reported in human (LaMotte et al., 1992). As shown here, some of the mechanically insensitive $\mathrm{CH}$ and $\mathrm{CM}_{\mathrm{i}} \mathrm{H}_{\mathrm{i}}$ units did indeed become mechanoresponsive after chemical irritation, as has also been observed in the skin of rat (Kress et al., 1992) and monkey (Davis et al., 1993). Such sensitization may contribute to primary hyperalgesia to static pressure after topical application of capsaicin and mustard oil (Culp et al., 1989; Koltzenburg et al., 1992; Kilo et al., 1994).

Thus, our study contributes the proof of recruitment of further, previously silent units into the sensitized state in humans. While sensitization of previously responsive units leads to temporal summation of the nociceptive input on central neurons, the recruitment of previously silent units will add a component of spatial summation (Handwerker and Reeh, 1991; Kress et al., 1992). Our results indicate that spatial summation from newly recruited sensitized $C$ nociceptors can contribute to primary heat and mechanical hyperalgesia due to chemical irritants. Furthermore, it is conceivable that different classes of nociceptive units may have different central connections and may release different types and amounts of neurotransmitters. For instance, it has been shown that the neuropeptide release in the spinal cord differs in normal versus arthritic cats (Schaible 
et al., 1990). Thus, it is possible that the recruitment of previously unresponsive nociceptors may cause or enhance central sensitization that may express itself as various forms of secondary hyperalgesia (LaMotte et al., 1991). Our demonstration of the existence of chemonociceptors in human skin adds support for this thcory.

\section{References}

Adriaensen H, Gybels J, Handwerker HO, Van Hees J (1983) Response properties of thin myelinated (A-delta) fibers in human skin nerves. J Neurophysiol 49:111-122.

Baron R, Jänig W, Kollmann W (1988) Sympathetic and afferent somata projecting in hind limb nerves and the anatomical organization of the lumbar sympathetic nervous system of the rat. J Comp Neurol 275:460-468.

Baumann TK, Simone DA, Shain CN, LaMotte RH (1991) Neurogenic hyperalgesia: the search for the primary cutaneous afferent fibers that contribute to capsaicin-induced pain and hyperalgesia. J Neurophysiol 66:212-227.

Beck PW, Handwerker HO, Zimmermann M (1974) Nervous outflow from the cat's foot during noxious radiant heat stimulation. Brain Res 67:373-386.

Bessou P, Perl ER (1969) Responses of cutaneous sensory units with unmyelinated fibers to noxious stimuli. J Neurophysiol 32:1025-1043.

Campbell JN, Raja SN, Cohen RH, Manning DC, Khan AA, Meyer RA (1989) Peripheral neural mechanisms of nociception. In: Textbook of pain (Wall PD, Melzack R, eds), pp 22-45. London: Churchill Livingstone.

Culp WJ, Ochoa J, Cline M, Dodtson R (1989) Heat and mechanical hyperalgesia induced by capsaicin. Brain 112:1317-1331.

Davis KD, Meyer RA, Campbell JN (1993) Chemosensitivity and sensitization of nociceptive afferents that innervate the hairy skin of monkey. J Neurophysiol 69:1071-1081.

Delius W, Hagbarth K-E, Hognell A, Wallin BG (1972) Manoeuvres affecting sympathetic outflow in human skin nerves. Acta Physiol Scand 84:177-186.

Forster C, Handwerker HO (1990) Automatic classification and analysis of microneurographic spike data using a PC/AT. J Neurosci Methods 31:109-118.

Georgopoulos AP (1976) Functional properties of primary afferent units probably related to pain mechanisms in primate glabrous skin. J Neurophysiol 39: 71-83.

Grigg P, Schaible H-G, Schmidt RF (1986) Mechanical sensitivity of group III and IV afferents from posterior articular nerve in normal and inflamed cat knee. J Neurophysiol 55:635-643.

Gybels J, Handwerker HO, Van Hees J (1979) A comparison between the discharges of human nociceptive nerve fibres and the subject's ratings of his sensations. J Physiol (Lond) 292:193-206.

Häbler H-J, Jänig W, Koltzenburg M (1988) A novel type of unmyelinated chemoscnsitive nociccptor in the acutely inflamed urinary bladder. Agents Actions 25:219-221.

Häbler H-J, Jänig W, Koltzenburg M (1990) Activation of unmyelinated afferent fibres by mechanical stimuli and inflammation of the urinary bladder in the cat. J Physiol (Lond) 425:545-562.

Hagbarth K-E, Hallin RG, Hognell A, Torebjörk HE, Wallin BG (1972) General characteristics of sympathetic activity in human skin nerves. Acta Physiol Scand 84:164-176.

Hallin RG, Torebjörk HE (1970) Afferent and efferent C units recorded from human skin nerves in situ. A preliminary report. Acta Soc Med Ups 75:277-281.

Hallin RG, Torebjörk HE (1974a) Single unit sympathetic activity in human skin nerves during rest and various manoeuvres. Acta Physiol Scand 91:303-317.

Hallin RG, Torcbjörk HE (1974b) Mcthods to differentiatc clcctrically induced afferent and sympathetic $\mathrm{C}$ unit responses in human cutaneous nerves. Acta Physiol Scand 92:318-331.

Hallin RG, Torebjörk HE, Wiesenfeld Z (1982) Nociceptors and warm receptors innervated by $\mathrm{C}$ fibres in human skin. J Neurol Neurosurg Psychiatr 45:313-319.

Handwerker HO, Kobal G (1993) Psychophysiology of experimentally induced pain. Physiol Rev 73:639-671.

Handwerker HO, Reeh PW (1991) Pain and Inflammation. In: Proceedings of the VIth World Congress on Pain (Bond MR, Charlton JE, Woolf CJ, eds), pp 59-69. Amsterdam: Elsevier.
Handwerker HO, Forster C, Kirchhoff C (1991a) Discharge patterns of human $C$-fibers induced by itching and burning stimuli. J Neurophysiol 66:307-315.

Handwerker HO, Kilo S, Reeh PW (1991b) Unresponsive afferent nerve fibres in the sural nerve of the rat. J Physiol (Lond) 435:229242.

Handwerker HO, Schmidt R, Forster C, Schmelz M, Traversa R, Torebjörk HE (1993) Microneurographic assessment of sensitive and insensitive C-fibers in a human skin nerve. Soc Neurosci Abstr 19: 1404.

Hensel H (1976) Correlations of human activity and thermal sensation in man. In: Sensory functions of the skin in primates (Zotterman Y, ed), pp 331-353. Paris: Pergamon.

Iggo A (1960) Cutaneous mechanoreceptors with afferent C fibres. J Physiol (Lond) 152:337-353.

Jancsó N, Jancsó-Gábor A, Szolcsanyi J (1967) Direct evidence for neurogenic inflammation and its prevention by denervation and by pretreatment with capsaicin. Br J Pharmacol 31:138-151.

Jänig W (1984) Patterns of activity in postganglionic vasoconstrictor neurones in vivo. In: Progress in microcirculation research II (Courtice FC, Garlick DG, Perry MA, eds), pp 336-345. Sydney: University of NSW (Committee in Postgraduate Medical Education).

Jänig W (1988) Pre- and postganglionic vasoconstrictor neurons: differentiation, types, and discharge properties. Annu Rev Physiol 50: 525-539.

Jänig W, Sundlof G, Wallin BG (1983) Discharge patterns of sympathetic neurons supplying skeletal muscle and skin in man and cat. J Auton Nerv Syst 7:239-256.

Jørum E, Lundberg, LER, Torebjörk HE (1989) Peripheral projections of nociceptive unmyelinated axons in the human peroneal nerve. $J$ Physiol (Lond) 416:291-301.

Kilo S, Schmelz M, Koltzenburg M and Handwerker HO (1994) Different patterns of hyperalgesia induced by experimental inflammations in human skin. Brain, in press.

Koltzenburg M, Lundberg LER, Torebjörk HE (1992) Dynamic and static components of mechanical hyperalgesia in human hairy skin. Pain 51:207-219.

Kress M, Koltzenburg M, Reeh PW, Handwerker HO (1992) Responsiveness and functional attributes of electrically localized terminals of cutaneous $\mathrm{C}$-fibers in vivo and in vitro. J Neurophysiol 68: 581-595.

Kumazawa T, Perl ER (1977) Primate cutaneous sensory units with unmyelinated (C) afferent fibers. J Neurophysiol 40:1325-1338.

LaMotte RH (1988) Psychophysical and neurophysiological studies of chemically induced cutaneous pain and itch. The case of the missing nociceptor. Prog Brain Res 74:331-335.

LaMotte RH (1992) Subpopulations of "nocifensor neurons" contributing to pain and allodynia, itch and allokinesis. APS J 1:115126.

LaMotte RH, Simone DA, Baumann TK, Shain CN, Alreja M (1988) Hypothesis for novel classes of chemoreceptors mediating chemogenic pain and itch. In: Proceedings of the Vth World Congress on Pain (Dubner R, Gebhart GF, Bond M, eds), pp 529-535. Amsterdam: Elsevier.

LaMotte RH, Shain CN, Simone DA and Tsai EF (1991) Neurogenic hyperalgesia: psychophysical studies of underlying mechanisms. J Neurophysiol 66:190-211.

LaMotte RH, Lundberg LER, Torebjörk HE (1992) Pain, hyperalgesia and activity in nociceptive $\mathrm{C}$ units in humans after intradermal injection of capsaicin. J Physiol (Lond) 448:749-764.

Meyer RA, Campbell JN (1988) A novel electrophysiological technique for locating cutaneous nociceptive and chemospecific receptors. Brain Res 441:81-86.

Meyer RA, Davis KD, Cohen RH, Treede RD, Campbell JN (1991) Mechanically insensitive afferents (Mias) in cutaneous nerves of monkey. Brain Res 561:252-261.

Neugebauer V, Schaible H-G, Schmidt RF (1989) Sensitization of articular afferents to mechanical stimuli by bradykinin. Pfluegers Arch 415:330-335.

Nordin M (1990) Low-threshold mechanoreceptive and nociceptive units with unmyelinated $(C)$ fibres in the human supraorbital nerve. J Physiol (Lond) 426:229-240.

Schaible H-G, Schmidt RF (1985) Effects of an experimental arthritis on the sensory properties of fine articular afferent units. J Neurophysiol 54:1109-1122.

Schaible H-G, Schmidt RF (1988) Time course of mechanosensitivity 
changes in articular afferents during a developing experimental arthritis. J Neurophysiol 60:2180-2195.

Schaible H-G, Jarrott PJ, Hope AW, Duggan AW (1990) Release of immunoreactive substance $P$ in the cat spinal cord during development of acute arthritis in cat's knee: a study with antibody bearing microprobes. Brain Res 529:214-223.

Simone DA, Ngeow JY, Putterman GJ, LaMotte RH (1987) Hyperalgesia to heat after intradermal injection of capsaicin. Brain Res 418: 201-203.

Szolcsanyi J (1988) Antidromic vasodilatation and neurogenic inflammation. Agents Actions 23:4-11.

Torebjörk HE (1974) Afferent $C$ units responding to mechanical, thermal and chemical stimuli in human non-glabrous skin. Acta Physiol Scand 92:374-390.

Torebjörk HE, Hallin RG (1970) C-fibre units recorded from human sensory nerve fascicles in situ. A preliminary report. Acta Soc Med Ups 75:81-84.

Torebjörk HE, Hallin RG (1974) Responses in human A and C fibres to repeated electrical intradermal stimulation. J Neurol Neurosurg Psychiatr 37:653-664.
Torebjörk HE, Hallin RG (1976) A new method for classification of $\mathrm{C}$-unit activity in intact human skin nerves. In: Advances in pain research and therapy, Vol 1 (Bonica JJ, Albe-Fessard D, eds), pp 2934. New York: Raven.

Torebjörk HE, LaMotte RH, Robinson CJ (1984) Peripheral neural correlates of magnitude of cutaneous pain and hyperalgesia: simultaneous recordings in humans of sensory judgments of pain and evoked responses in nociceptors with C-fibers. J Neurophysiol 51:325-339.

Vallbo AB, Hagbarth K-E, Torebjörk HE, Wallin BG (1979) Somatosensory, proprioceptive and sympathetic activity in human peripheral nerves. Physiol Rev 59:919-957.

Van Hees J, Gybels J (1981) C nociceptor activity in human nerve during painful and non painful skin stimulation. $J$ Neurol Neurosurg Psychiatr 44:600-607.

Welk E, Fleischer E, Petsche U, Handwerker HO (1984) Afferent C-fibres in rats after neonatal capsaicin treatment. Pfluegers Arch 400: 66-71. 